\title{
EFICIÊNCIA AGRONÔMICA DE RIZÓBIOS SELECIONADOS E DIVERSIDADE DE POPULAÇÕES NATIVAS NODULÍFERAS EM PERDÕES (MG). II - FEIJOEIRO ${ }^{(1)}$
}

\author{
André Luis de Lima Soares ${ }^{(2)}$, Paulo Ademar Avelar Ferreira ${ }^{(3)}$, João \\ Paulo Andrade Resende Pereira ${ }^{(3)}$, Helson Mário Martins do Vale ${ }^{(4)}$, \\ Adriana Silva Lima ${ }^{(5)}$, Messias José Bastos de Andrade ${ }^{(6)}$ \& Fátima \\ Maria de Souza Moreira ${ }^{(7)}$
}

\begin{abstract}
RESUMO
O feijão (Phaseolus vulgaris L.) é um dos principais constituintes da dieta do brasileiro, por ser excelente fonte protéica e, portanto, um produto agrícola de grande importância econômico-social. A interação do feijoeiro com bactérias fixadoras de $\mathrm{N}$ atmosférico pode aumentar a produtividade e diminuir os custos de produção. No presente trabalho, avaliou-se, no campo, a eficiência agronômica de estirpes previamente selecionadas de rizóbio em simbiose com o feijoeiro, comparadas à estirpe recomendada para a produção de inoculantes comerciais (CIAT 899). A diversidade fenotípica da população nativa foi avaliada pela análise das características culturais e pela análise de proteína total por eletroforese em gel poliacrilamida (SDS-PAGE). Verificou-se que a inoculação no campo com as estirpes UFLA 02-100, UFLA 02-86 e UFLA 02-127 promoveu rendimento de grãos semelhante ao da testemunha, com $70 \mathrm{~kg} \mathrm{ha}^{-1}$ de $\mathrm{N}$, e à inoculação com a estirpe de referência CIAT 899. Não houve relação entre os grupos fenotípicos de perfil protéico total e caracterização cultural constituídos pelas estirpes nativas do solo. As populações nativas que nodularam feijão mostraram-se bastante diversas fenotipicamente e não incluíram estirpes similares às estirpes introduzidas como inoculantes.
\end{abstract}

Termos de indexação: Phaseolus vulgaris, rizóbio, fixação biológica de $\mathrm{N}_{2}$, produtividade.

\footnotetext{
(1) Artigo retirado de dissertação de Mestrado e recebido para publicação em julho de 2005 e aprovado em setembro de 2006.

(2) Mestre em Solos e Nutrição de Plantas - UFLA. Caixa Postal 3037, CEP 37200-000 Lavras (MG). Bolsista do CNPq. E-mail: andrellsoares@hotmail.com

(3) Engenheiro-Agrônomo, Agronomia, UFLA. Bolsistas PIBIC/CNPq. E-mail: pauloufla@yahoo.com.br; joaopauloufla@yahoo.com.br.

(4) Mestrando em Microbiologia Agrícola, UFLA. Bolsista da CAPES. E-mail: helsomario@yahoo.com.br

${ }^{(5)}$ Doutoranda em Solos e Nutrição de Plantas, UFLA. Bolsista da CAPES. E-mail: adrianalima@navinet.com.br

(6) Professor do Departamento de Agronomia, DAG/UFLA. Bolsista do CNPq. E-mail: mandrade@ufla.br

(7) Professora do Departamento de Ciência do Solo, DCS/UFLA. Bolsista do CNPq. E-mail: fmoreira@ufla.br
} 


\title{
SUMMARY: AGRONOMIC EFFICIENCY OF SELECTED RHIZOBIA STRAINS AND DIVERSITY OF NATIVE NODULATING POPULATIONS IN PERDÕES (MG - BRAZIL). II - BEANS
}

\begin{abstract}
Common bean (Phaseolus vulgaris L.) is an economically and socially highly relevant staple food and an excellent protein source for the Brazilian population. Symbiosis of beans and $\mathrm{N}_{2}$ fixing bacteria can increase yields and decrease yield costs. The first aim of this study was to evaluate the agronomic efficiency of previously selected rhizobia strains compared to the recommended strain (CIAT 899). Phenotypic diversity of rhizobia native populations was evaluated by cultural characteristics and analysis of total protein profiles by polyacrilamide gel electrophoresis (SDS-PAGE). Field inoculations with strains UFLA 02-100, UFLA 02-86 and UFLA 02-127 increased grain yields similarly to the control with $70 \mathrm{~kg} \mathrm{ha}^{-1} \mathrm{~N}$-urea and strain CIAT 899, compared to the control without inoculation and mineral $N$. No relation was observed between the phenotypic grouping according to cultural characteristics or protein profiles. Native bean-nodulating populations are quite diverse and do not include strains similar to the strains introduced as inoculants
\end{abstract}

Index terms: Phaseolus vulgaris, Bradyrhizobium, biological $N_{2}$ fixation, yield.

\section{INTRODUÇÃO}

O feijão (Phaseolus vulgaris L.) é um dos principais constituintes da dieta do brasileiro por ser uma excelente fonte protéica. É, ainda, um produto agrícola de grande importância econômico-social. No Brasil, a produtividade média de feijão, nos últimos três anos, evoluiu de cerca de $700 \mathrm{~kg} \mathrm{ha}^{-1}(2001 / 2002)$ para $826 \mathrm{~kg} \mathrm{ha}^{-1}$ (2003/2004) (www.conab.gov.br), enquanto, em outros países, como Estados Unidos e China, estas produtividades estão em torno de $1.200 \mathrm{e}$ $1.800 \mathrm{~kg} \mathrm{ha}^{-1}$, respectivamente (Faostat, 2003).

O cultivo de feijão no Brasil é caracterizado por dois sistemas produtivos: lavouras menores que 100 ha, correspondendo a $71 \%$ da produção nacional e com produtividade média de $525 \mathrm{~kg} \mathrm{ha}^{-1}$, e lavouras maiores que 100 ha, que empregam tecnologia superior e apresentam produtividade média de $1.440 \mathrm{~kg} \mathrm{ha}^{-1}$. Nas primeiras, destaca-se a necessidade do desenvolvimento de tecnologias de baixo custo, capazes de melhorar a produtividade dos pequenos agricultores (Strallioto, 2002).

Um dos fatores mais limitantes à produtividade do feijoeiro é a baixa disponibilidade de nutrientes, sobretudo $\mathrm{P}$ e N, nos solos agrícolas. A adição de N na forma de fertilizantes é cara e, em muitos casos, pouco eficiente, sobretudo em decorrência de perdas do elemento causadas por práticas culturais inadequadas (Araújo, 1994).

Como muitas espécies leguminosas, o feijoeiro também é capaz de estabelecer simbiose com bactérias fixadoras de $\mathrm{N}_{2}$, podendo, assim, garantir parte de suas exigências em $\mathrm{N}$ por meio do processo de fixação biológica. Resultados de pesquisa apontam que é possível a cultura do feijoeiro se beneficiar, no campo, da fixação biológica de $\mathrm{N}_{2}$ (Araújo, 1994), e o grande desafio que se apresenta é conseguir um manejo adequado dessa simbiose, visando aumentar a sua eficiência em níveis próximos ou similares aos obtidos com a cultura da soja.

A seleção de novas estirpes, capazes de fixar $\mathrm{N}$ atmosférico quando em simbiose com o feijoeiro, é uma ferramenta importante na busca de um par simbiótico mais eficiente. Contudo, estirpes selecionadas em laboratório e casa de vegetação podem não alcançar o máximo potencial de fixação no campo, em decorrência, dentre outros fatores, da competição com a população nativa e estabelecida do solo e da baixa adaptação às condições ambientais locais.

A espécie de rizóbio recomendada para produção de inoculantes para a cultura do feijoeiro é Rhizobium tropici (Martinez-Romero et al., 1991), compreendendo as estirpes comerciais SEMIA 4077 (CIAT 899) e SEMIA 4080 (PRF 81). Esta espécie é relatada como sendo geneticamente mais estável e mais tolerante a estresses que outras espécies de rizóbio, como temperaturas elevadas e acidez do meio, sendo mais adaptada às condições de solos tropicais (Graham, 1992). No entanto, outras espécies de rizóbio devem ser testadas neste sentido, principalmente aquelas oriundas de solos ácidos e com altas temperaturas como os da Amazônia, que, teoricamente, também estão adaptadas a estas condições.

Hungria et al. (2000), comparando a eficiência de novos isolados de rizóbio para o feijoeiro no estado do Paraná, juntamente com estirpes de Rhizobium tropici, verificaram que a inoculação proporcionou acréscimo de até $900 \mathrm{~kg} \mathrm{ha}^{-1}$ no rendimento de grãos, em relação ao controle sem inoculação e sem adubação com $\mathrm{N}$, e que a maioria dos rendimentos obtidos por 
meio da inoculação foi semelhante ao do controle que recebeu completa adubação nitrogenada. Do mesmo modo, Mostasso et al. (2001) também verificaram que, no feijoeiro, a inoculação de novas estirpes de rizóbio, isoladas no Distrito Federal, proporcionou rendimentos semelhantes aos da testemunha que recebeu adubação nitrogenada, e das estirpes de referência de Rhizobium tropici (CIAT 899 e PRF 81).

Utilizando os mesmos isolados obtidos por Mostasso et al. (2001), Hungria et al. (2003) obtiveram resposta com a inoculação de alguns isolados, os quais proporcionaram rendimentos médios de até $1.600 \mathrm{~kg} \mathrm{ha}^{-1}$, igualando-se à inoculação com as estirpes de referência, CIAT 899 e PRF 81, e ao controle com $\mathrm{N}$ de fertilizantes.

O objetivo do presente trabalho foi avaliar a eficiência agronômica de estirpes de rizóbio previamente selecionadas em condições controladas, em simbiose com o feijão no campo e a comparação destas com uma das estirpes recomendadas para a produção de inoculante comercial para a cultura. Também foram avaliadas a densidade e a diversidade fenotípica de populações de bactérias nativas que nodulam o feijão na área em estudo.

\section{MATERIAL E MÉTODOS}

\section{Ensaio de campo}

O ensaio de campo foi realizado em área experimental do município de Perdões, Minas Gerais, na safra das águas de 2002/2003, em um Argissolo Vermelho distrófico típico (Embrapa, 2000), em área onde não havia sido cultivado feijão e sem utilização de qualquer inoculante. Os resultados da análise química de amostra do solo encontram-se no quadro 1. O cultivo se deu em condição de baixa utilização de insumos, não tendo sido aplicados calagem, micronutrientes ou defensivos fitossanitários. O ensaio foi realizado de acordo com as recomendações da Rede de Laboratórios para Recomendação, Padronização e Difusão de Tecnologia de Inoculantes Microbiológicos de Interesse Agrícola (RELARE).

Foi utilizado o cultivar BRSMG Talismã, de grão tipo carioca, lançado em 2002, e que apresenta resistência à antracnose e ao vírus do mosaico comum, sendo, ainda, moderadamente resistente à mancha angular (Ramalho et al., 2002).

O delineamento experimental utilizado foi o de blocos casualizados com quatro repetições e sete tratamentos: testemunhas sem inoculação, sendo uma sem N, outra que recebeu adubação nitrogenada na dose de $70 \mathrm{~kg} \mathrm{ha}^{-1}$ de $\mathrm{N}$ (fonte uréia), quatro estirpes de rizóbio, UFLA 02-100, UFLA 02-68, UFLA 02-86 e UFLA 02-127 (Quadro 2) e uma estirpe de referência (CIAT 899), recomendada pela RELARE como inoculante para a cultura do feijão. As seqüências de
Quadro 1. Características químicas de amostra do solo (profundidade de $0-20 \mathrm{~cm}$ ) antes da adubação e da semeadura ${ }^{(1)}$

\begin{tabular}{|c|c|c|}
\hline Característica & Unidade & Valor \\
\hline pH em $\mathrm{H}_{2} \mathrm{O}(1: 2,5)$ & & 4,9 \\
\hline P (Mehlich-1) & $\mathrm{mg} \mathrm{dm}{ }^{-3}$ & 14,5 \\
\hline K (Mehlich-1) & $\mathrm{mg} \mathrm{dm}{ }^{-3}$ & 122 \\
\hline $\mathrm{Ca}^{2+}$ & $\mathrm{cmol}_{\mathrm{C}} \mathrm{dm}^{-3}$ & 2,0 \\
\hline $\mathrm{Mg}^{2+}$ & $\mathrm{cmol}_{\mathrm{c}} \mathrm{dm}^{-3}$ & 0,6 \\
\hline $\mathrm{Al}^{3+}$ & $\mathrm{cmol}_{\mathrm{c}} \mathrm{dm}^{-3}$ & 0,3 \\
\hline $\mathrm{H}+\mathrm{Al}$ & $\mathrm{cmol}_{\mathrm{C}} \mathrm{dm}^{-3}$ & 4,5 \\
\hline S.B & $\mathrm{cmol}_{\mathrm{C}} \mathrm{dm}^{-3}$ & 2,9 \\
\hline $\mathrm{t}$ & $\mathrm{cmol}_{\mathrm{c}} \mathrm{dm}^{-3}$ & 3,2 \\
\hline $\mathrm{T}$ & $\mathrm{cmol}_{\mathrm{c}} \mathrm{dm}^{-3}$ & 7,4 \\
\hline $\mathrm{m}$ & $\%$ & 9,0 \\
\hline V & $\%$ & 39,3 \\
\hline Matéria orgânica & dag $\mathrm{kg}^{-1}$ & 1,9 \\
\hline
\end{tabular}

(1) Análises realizadas nos Laboratórios do Departamento de Ciências do Solo da UFLA.

16 S rDNA das estirpes UFLA 2-100 e UFLA 2-68 revelaram que essas são similares a Rhizobium sp. estirpe CIAT 652 (AF313906), a respectivamente 99 e $89 \%$ de similaridade. Já as estirpes UFLA 2-86 e UFLA 2-127 têm seu gene nod C similar ao nod C de R.leguminosarum AF 217263 , a 92 e $97 \%$ de similaridade, respectivamente (Moreira, dados não publicados). Todas as estirpes testadas foram isoladas de nódulos de feijoeiro em solos da Amazônia, em maio de 1997, e mantiveram, desde então, sua estabilidade genética com relação as características relacionadas com simbiose eficiente com feijão.

O solo foi preparado com uma aração e uma gradagem. A semeadura, na densidade de 15 sementes por metro de sulco, foi feita em 30 de novembro de 2002 , após a inoculação das sementes com seus respectivos tratamentos. As parcelas foram constituídas por seis linhas de $6 \mathrm{~m}$ de comprimento, espaçadas em $0,50 \mathrm{~m}$, totalizando $18 \mathrm{~m}^{2}$ de área total e $5 \mathrm{~m}^{2}$ de área útil.

O inoculante foi preparado com turfa esterilizada em autoclave, na proporção 3:1 de turfa e culturas em meio 79 (Fred \& Waksman, 1928) semi-sólido na fase log, inoculando-se $500 \mathrm{~g}$ do inoculante para cada $50 \mathrm{~kg}$ de sementes. Todos os tratamentos, incluindo as testemunhas, receberam adubação fosfatada e potássica à base de $70 \mathrm{~kg} \mathrm{ha}^{-1} \mathrm{de}_{2} \mathrm{O}_{5} \mathrm{e} 40 \mathrm{~kg} \mathrm{ha}^{-1} \mathrm{de}$ $\mathrm{K}_{2} \mathrm{O}$, usando, como fontes, superfosfato triplo e cloreto de $\mathrm{K}$, respectivamente. Além desta adubação, a testemunha nitrogenada recebeu $70 \mathrm{~kg} \mathrm{ha}^{-1}$ de $\mathrm{N}$, parcelados em duas vezes: $35 \mathrm{~kg} \mathrm{ha}^{-1}$ de $\mathrm{N}$ aplicados na semeadura e $35 \mathrm{~kg} \mathrm{ha}^{-1}$ de N aplicados 20 dias após a emergência. 
Quadro 2. Origem (Sistema de Uso da Terra-SUT; Município, Estado e País) e características culturais das estirpes de rizóbios usadas no ensaio e dos grupos de isolados nativos

\begin{tabular}{|c|c|c|c|c|c|c|c|}
\hline \multirow{2}{*}{$\begin{array}{l}\text { Identificação da } \\
\text { estirpe ou do } \\
\text { grupo de rizóbio }\end{array}$} & \multirow[b]{2}{*}{ SUT/ Município/Estado/País } & \multirow[b]{2}{*}{$\operatorname{ACI}(1)$} & \multicolumn{5}{|c|}{ Característica cultural } \\
\hline & & & $\mathbf{D}^{(2)}$ & $P^{(3)}$ & $\mathbf{P H}^{(4)}$ & $\mathbf{A} \mathbf{I}^{(5)}$ & $\operatorname{COR}^{(6)}$ \\
\hline UFLA 02-68 & Capoeira, Theobroma, RO, BR & 3 & $>2$ & Alta & Neutro & Sim & Branca \\
\hline UFLA $02-86$ & Capoeira, Theobroma, RO, BR & 3 & $>2$ & Alta & Neutro & Sim & Branca \\
\hline UFLA $02-100$ & Capoeira, Theobroma, RO, BR & 3 & $>2$ & Alta & Neutro & Sim & Branca \\
\hline UFLA $02-127$ & Capoeira, Theobroma, RO, BR & 3 & $>2$ & Alta & Neutro & Sim & Branca \\
\hline CIAT 899 & Colômbia & 3 & $>2$ & Alta & Ácido & Não & Amarela \\
\hline Grupo A & Pastagem, Perdões MG, BR & 2 a 3 & $>2$ & Alta & Ácido & Sim & Amarela \\
\hline Grupo B & Pastagem, Perdões MG, BR & 2 a 3 & 1 a 2 & Alta & Ácido & Sim & Amarela \\
\hline Grupo C & Pastagem, Perdões MG, BR & 2 a 3 & $>2$ & Média & Ácido & Sim & Amarela \\
\hline Grupo D & Pastagem, Perdões MG, BR & 2 a 3 & $>2$ & Alta & Neutro & Não & Branca \\
\hline Grupo E & Pastagem, Perdões MG, BR & 2 a 3 & $>2$ & Alta & Ácido & Sim & Amarela \\
\hline
\end{tabular}

(1) Tempo em dias de crescimento de colônias isoladas. ${ }^{(2)}$ Diâmetro da colônia (mm). ${ }^{(3)}$ Produção de goma. ${ }^{(4)}$ Alteração do pH meio de cultivo. ${ }^{(5)}$ Absorção de indicador do meio de cultura indicada pela coloração amarela/azul no centro das colônias. ${ }^{(6)}$ Coloração das colônias.

Por ocasião do florescimento, foram coletadas 10 plantas de cada parcela, na segunda e quinta linha, para avaliação da nodulação (número e massa de matéria seca) e parte aérea (produção de matéria seca, teor e acúmulo de $\mathrm{N}$ e eficiência relativa). Foram avaliados o rendimento de grãos (com sua umidade corrigida para $13 \%$ ) e o teor de $\mathrm{N}$ nos grãos.

O N total foi determinado pelo método semimicrokjeldahl, de acordo com Sarruge \& Haag (1979), na matéria seca da parte aérea e nos grãos. O N acumulado na parte aérea foi calculado, multiplicandose o peso da matéria seca da parte aérea pelo teor de $\mathrm{N}$.

A eficiência relativa de cada parcela foi calculada pela expressão:

$$
\text { Efr }=\frac{\text { MSPAinocul ada }}{\text { MSPAcomN }} \times 100
$$

sendo Efr: eficiência relativa; MSPA inoculada: matéria seca da parte aérea da planta inoculada; MSPA com N: matéria seca da parte aérea da planta com N.

\section{Densidade e diversidade fenotípica de populações nativas que nodulam o feijoeiro}

O experimento para a captura, contagem e avaliação da eficiência de rizóbios foi realizado, em vasos de Leonard, no Laboratório de Microbiologia do Solo/DCS/UFLA, nos meses de setembro e outubro de 2003, utilizando, como planta-isca, o mesmo cultivar de feijão do experimento de campo.

O delineamento estatístico empregado foi o inteiramente casualizado, com seis repetições e nove tratamentos. Os tratamentos foram as inoculações com $1 \mathrm{~mL}$ de suspensão de solo proveniente das diluições seriadas, de $10^{-1}$ a $10^{-7}$ em solução salina $\left(5,5 \mathrm{~g} \mathrm{~L}^{-1} \mathrm{de}\right.$ $\mathrm{NaCl}$ ), além de duas testemunhas sem inoculação, sendo uma sem adição de $\mathrm{N}$ e outra com aplicação de $\mathrm{N}$ parcelada em três vezes, em a intervalos de 10 dias, totalizando $210 \mathrm{mg}$ vaso ${ }^{-1}$ de $\mathrm{N}$ na forma de $\mathrm{NH}_{4} \mathrm{NO}_{3}$.

A parte superior dos vasos de Leonard continha uma mistura 1:1 de areia e vermiculita, enquanto a inferior continha solução nutritiva de Jensen modificada $\left(\mathrm{K}_{2} \mathrm{HPO}_{4} 0,2 \mathrm{~g} \mathrm{~L}^{-1} ; \mathrm{MgSO}_{4} \cdot 7 \mathrm{H}_{2} \mathrm{O} 0,2 \mathrm{~g} \mathrm{~L}^{-1}\right.$, $\mathrm{NaCl} 0,2 \mathrm{~g} \mathrm{~L}^{-1}, \mathrm{CaHPO}_{4} 1 \mathrm{~g} \mathrm{~L}^{-1}, \mathrm{FeCl}_{3} .6 \mathrm{H}_{2} \mathrm{O} 0,1 \mathrm{~g} \mathrm{~L}^{-1}$, em $1 \mathrm{~mL}$ sol. micronutrientes), diluída quatro vezes e autoclavada, por $30 \mathrm{~min}$, a $1,5 \mathrm{~kg} \mathrm{~cm}^{-2}$ e a $127^{\circ} \mathrm{C}$. Após o preparo, os vasos foram autoclavados, por $1 \mathrm{~h}$, à pressão de $1,5 \mathrm{~kg} \mathrm{~cm}^{-2} \mathrm{e}$ a $127^{\circ} \mathrm{C}$.

As sementes utilizadas foram desinfetadas superficialmente com etanol $70 \%$, por $5 \mathrm{~min}$, e hipoclorito de sódio a $1 \%$, por $3 \mathrm{~min}$. Em seguida, foram lavadas seis vezes com água destilada esterilizada. Posteriormente, foram semeadas quatro sementes por vaso. Também foi colocada, sobre a superfície do vaso, uma fina camada de mistura esterilizada de areia, benzeno e parafina (proporção de 5:1:0,015, respectivamente), com a finalidade de evitar possíveis contaminações.

Decorridos três a cinco dias após a germinação, foi feito o desbaste, deixando-se somente uma planta por vaso. As plantas foram colhidas por ocasião do florescimento (35 dias após a emergência) para determinação da nodulação (presença ou ausência), produção de matéria seca da parte aérea e para isolamento das bactérias nativas presentes nos nódulos. 
Para estimar o número mais provável (NMP) de células de rizóbio nas duas amostras coletadas, considerou-se positivo para presença e negativo para ausência de nódulos, em cada diluição, usando o programa "Most Probable Number Estimate" (MPNES) (Woomer et al., 1990).

Três nódulos de cada planta-isca foram utilizados para o isolamento de rizóbios nativos. Estes nódulos foram primeiramente imersos em álcool etílico $95 \%$, por 30 seg, e, posteriormente, imersos em $\mathrm{H}_{2} \mathrm{O}_{2}$, por 1 min, e, depois, lavados seis vezes com água estéril. Os nódulos foram então esmagados em placas que continham meio de cultura 79 (Fred \& Waksman, 1928), sendo o material interno espalhado nas placas para a obtenção de colônias isoladas.

Obtidas as colônias isoladas e puras e crescidas em placas com meio de cultura 79 , foram avaliadas as seguintes características culturais dos isolados: taxa de crescimento, medida pelo tempo de aparecimento de colônias isoladas (rápido - 2 a 3 dias; intermediário -4 a 5 dias; lento -6 a 10 dias; muito lento > 10 dias); diâmetro médio no aparecimento de colônias isoladas ( $<1 \mathrm{~mm}, 1$ a $2 \mathrm{~mm}$ e > $2 \mathrm{~mm}$ ); modificação do $\mathrm{pH}$ do meio (acidificação, alcalinização e neutro), produção de goma (baixa, média e alta) e coloração das colônias (amarela ou branca), conforme Moreira (1991).

Para a análise de proteínas totais por eletroforese em gel de poliacrilamida (SDS-PAGE) as estirpes usadas como inoculantes (Quadro 2), os isolados nativos, estirpes tipo e referência de espécies descritas foram então cultivados, por duas vezes sucessivas, em meio TY sólido, nas mesmas condições ambientais para todas as estirpes e isolados. Posteriormente, foi feita a inoculação dos isolados e estirpes em $50 \mathrm{~mL}$ de meio de cultura líquido TY. O crescimento ocorreu com agitação constante a $120 \mathrm{rpm}$ por 2 dias, à temperatura de $28^{\circ} \mathrm{C}$. O meio de crescimento com as bactérias foi então centrifugado a $10.000 \mathrm{rpm}$, por $10 \mathrm{~min}$, à temperatura de $4{ }^{\circ} \mathrm{C}$. O sobrenadante foi descartado e ao "pellet" formado foi adicionado o tampão NaPBS, que foi novamente centrifugado, repetindo-se esse processo três vezes. Foram pesados $70 \mathrm{mg}$ de células de cada isolado em tubo Eppendorf e, em seguida, adicionou-se $0,9 \mathrm{~mL}$ do tampão da amostra (TTA) mais $0,1 \mathrm{~mL}$ SDS $20 \%$, para a solubilização das proteínas. Posteriormente, aqueceuse a mistura em banho-maria a $95^{\circ} \mathrm{C}$, por $10 \mathrm{~min}$. Depois, as amostras foram centrifugadas a $12.000 \mathrm{rpm}$, por $10 \mathrm{~min}$, à temperatura de $4{ }^{\circ} \mathrm{C}$. Em seguida, as amostras foram submetidas à eletroforese em gel de poliacrilamida (PAGE), pelo método Laemmli (1970), com modificações descritas por Jackmam (1985), utilizadas para rizóbio por Moreira et al. (1993). Para a eletroforese, utilizou-se um gel de sistema descontínuo, $12 \%$ para o gel separador e $5 \%$ para o gel de concentração. Foram aplicados ao gel $30 \mu \mathrm{L}$ de cada amostra. Os grupos formados foram comparados com estirpes tipo de referência de espécies descritas e com as estirpes usadas como inoculante no ensaio de campo.
Os dados do ensaio de campo e do ensaio com vasos de Leonard foram submetidos à análise de variância, empregando-se o programa de análise estatística SISVAR, versão 4.0 .

Os dados de caracterização fenotípica pelo perfil protéico total das estirpes e dos isolados obtidos foram agrupados, utilizando o método UPGMA ("average linkage clustering"), cujo princípio baseia-se na distância intergrupo, que é a média das distâncias pareadas dos membros dos dois grupos e representados por um dendrograma de similaridade (NTSYS-pc, versão 2.01, Slice et al., 1994).

\section{RESULTADOS E DISCUSSÃO}

\section{Ensaio de campo}

Os valores médios das características avaliadas encontram-se no quadro 3. Os tratamentos influíram em todas as características avaliadas, exceto na eficiência relativa das estirpes. Em relação ao número de nódulos (NN), todas as estirpes permaneceram no mesmo grupo, igualando-se à Testemunha sem N, indicando boa nodulação por populações nativas de rizóbio (Quadro 3). A dose de $70 \mathrm{~kg} \mathrm{ha}^{-1}$ de $\mathrm{N}$ foi suficiente para inibir a nodulação por rizóbios nativos, tendo em vista que a testemunha com $\mathrm{N}$ foi a que apresentou menor $\mathrm{NN}$ e ficou no grupo inferior ao dos demais tratamentos.

Todas as estirpes testadas apresentaram quantidade de matéria seca de nódulos (MSN) semelhantes. As duas testemunhas apresentaram MSN inferior à das plantas inoculadas com as estirpes, ou seja, apesar de a testemunha sem $\mathrm{N}$ não ter diferido das estirpes quanto ao $\mathrm{NN}$, estes nódulos não apresentaram o mesmo peso em relação aos nódulos dos tratamentos que receberam inoculação, o que é indicativo de população com baixa eficiência. O tamanho (diâmetro) dos nódulos das plantas nas testemunhas foi menor do que o dos nódulos das plantas inoculadas, cerca de $2 \mathrm{~mm}$, para as testemunhas, e $3 \mathrm{~mm}$, para as plantas inoculadas.

Sabe-se que o pico da atividade da nitrogenase em feijoeiro ocorre depois da floração (Franco et al.,1979), posteriormente, portanto, ao período em que foram coletadas as plantas para determinação da MSPA. Contudo, a produção de MSPA foi afetada significativamente e a estirpe UFLA 02-127 destacouse das demais, ficando no mesmo grupo da testemunha com N (Quadro 3). Estes valores de eficiência relativa e de MSPA assemelham-se aos obtidos por Oliveira (1996), ao testar os efeitos da inoculação de estirpes de rizóbio sobre o feijoeiro, e após coleta de plantas no período do florescimento. A inoculação com a estirpe UFLA 02-127 proporcionou maior produção de matéria seca da parte aérea e mais acúmulo de $\mathrm{N}$ na parte aérea e se destacou das demais 
Quadro 3. Valores médios do número de nódulos por planta (NN), matéria seca de nódulos (MSN) $\left(\mathrm{mg} \mathrm{planta}^{-1}\right)$, matéria seca da parte aérea (MSPA) $\left(\mathrm{g} \mathrm{planta}^{-1}\right)$, eficiência relativa (Efr \%), acúmulo de N na parte aérea (ANPA) (mg planta $\left.{ }^{-1}\right)$, rendimento de grãos (RG) (kg ha $\left.{ }^{-1}\right)$, teor de $\mathrm{N}$ nos grãos (TNG) (\%) e acúmulo de $\mathrm{N}$ nos grãos (ANG) $\left(\mathrm{kg} \mathrm{ha}^{-1}\right)$, cultivar BRSMG-Talismã ${ }^{(1)}$

\begin{tabular}{|c|c|c|c|c|c|c|c|c|}
\hline Fonte de N & $\mathbf{N N}$ & MSN & MSPA & Efr & ANPA & $\mathbf{R G}$ & TNG & ANG \\
\hline & & mg planta ${ }^{-1}$ & g planta-1 & $\%$ & mg planta ${ }^{-1}$ & $\mathrm{~kg} \mathrm{ha} \mathrm{h}^{-1}$ & dag $h^{-1}$ & $\mathrm{~kg} \mathrm{ha} \mathrm{h}^{-1}$ \\
\hline Test. s/N & $56,00 \mathrm{a}$ & $118,35 \mathrm{~b}$ & $3,87 \mathrm{~b}$ & $66,64 \mathrm{a}$ & $128,85 \mathrm{~b}$ & $422,15 \mathrm{~b}$ & $3,28 \mathrm{~b}$ & $13,79 \mathrm{c}$ \\
\hline UFLA 02-100 & $69,32 \mathrm{a}$ & $195,85 \mathrm{a}$ & $4,17 \mathrm{~b}$ & 73,15 a & $166,59 \mathrm{~b}$ & $909,65 \mathrm{a}$ & $3,76 \mathrm{a}$ & $34,42 \mathrm{a}$ \\
\hline CIAT 899 & $70,87 \mathrm{a}$ & $206,90 \mathrm{a}$ & $4,37 \mathrm{~b}$ & $77,95 \mathrm{a}$ & $162,71 \mathrm{~b}$ & $974,64 \mathrm{a}$ & $3,82 \mathrm{a}$ & $37,04 \mathrm{a}$ \\
\hline UFLA 02-68 & $77,35 \mathrm{a}$ & $209,32 \mathrm{a}$ & $4,87 \mathrm{~b}$ & $96,03 \mathrm{a}$ & $175,90 \mathrm{~b}$ & $682,67 \mathrm{~b}$ & $3,58 \mathrm{a}$ & $24,59 \mathrm{~b}$ \\
\hline UFLA 02-86 & $70,90 \mathrm{a}$ & 208,65 a & $5,02 \mathrm{~b}$ & 88,78 a & $174,35 \mathrm{~b}$ & $877,61 \mathrm{a}$ & $3,62 \mathrm{a}$ & $31,58 \mathrm{a}$ \\
\hline UFLA $02-127$ & $79,92 \mathrm{a}$ & $226,77 \mathrm{a}$ & $6,58 \mathrm{a}$ & $116,60 \mathrm{a}$ & $245,35 \mathrm{a}$ & $826,43 \mathrm{a}$ & $3,54 \mathrm{a}$ & $29,33 \mathrm{a}$ \\
\hline Test. c/N & $31,52 \mathrm{~b}$ & $116,52 \mathrm{~b}$ & 5,92 a & $100,00 \mathrm{a}$ & $219,38 \mathrm{a}$ & $1041,81 \mathrm{a}$ & $3,74 \mathrm{a}$ & $38,55 \mathrm{a}$ \\
\hline CV (\%) & 26,40 & 11,14 & 21,84 & 26,81 & 23,29 & 22,78 & 5,31 & 21,73 \\
\hline
\end{tabular}

(1) Em cada coluna, médias seguidas pela mesma letra pertencem ao mesmo grupo, segundo o teste de Scott-Knott a 5 \%.

estirpes, permanecendo no mesmo grupo da testemunha com N, mostrando-se superior à estirpe de referência CIAT 899.

O rendimento médio de grãos variou de 422 a $1.041 \mathrm{~kg} \mathrm{ha}^{-1}$ (Quadro 3), atingindo, portanto, valores superiores aos da atual média nacional. A inoculação com as estirpes UFLA 02-100, UFLA 02-86 e UFLA 02-127 proporcionou rendimentos de grãos semelhantes aos da estirpe de referência CIAT $899 \mathrm{e}$ da testemunha com N. Somente a estirpe UFLA 0268 foi inferior às demais, permanecendo no mesmo grupo da testemunha sem N. Hungria et al. (2000), estudando a eficiência de novos isolados, obtiveram rendimentos de grãos superiores aos encontrados neste trabalho; houve resposta à inoculação de novas estirpes, tendo algumas, também, proporcionado rendimentos de grãos semelhante aos da estirpe de referência CIAT 899 e da testemunha com $\mathrm{N}$. Mostasso et al. (2001) também obtiveram rendimento de grãos superior a $2.000 \mathrm{~kg} \mathrm{ha}^{-1}$, considerando a inoculação com estirpes selecionadas. No entanto, as adubações de base com $\mathrm{P}$ e $\mathrm{K}$ usados por Hungria et al. (2000) e Mostasso et al. (2001) foram superiores às usadas em nossos experimentos, respectivamente $300 \mathrm{~kg} \mathrm{ha}^{-1}$ N-P-K (0-28-20) (Hungria et al., 2000) e $84 \mathrm{~kg} \mathrm{ha}^{-1}$ de $\mathrm{P}$ mais $60 \mathrm{~kg} \mathrm{ha}^{-1}$ de K (Mostasso et al., 2001). Além disso, esses autores também aplicaram $40 \mathrm{~kg} \mathrm{ha}{ }^{-1}$ de micronutrientes e Mostasso et al. (2001) ainda aplicaram calcário.

Todas as estirpes levaram a teores de N nos grãos semelhantes e permaneceram no mesmo grupo da testemunha com $\mathrm{N}$, sendo superiores ao da testemunha sem N. Já para acúmulo total de N nos grãos, a estirpe UFLA 02-68 foi inferior às demais. Este resultado é explicado pelo fato de tal estirpe também ter proporcionado menor rendimento de grãos em relação às outras.

Densidade e diversidade fenotípica de populações nativas que nodulam o feijoeiro

Nos ensaios em casa de vegetação com vasos Leonard, somente as plantas inoculadas com suspensão de solo até à diluição $10^{-4}$ apresentaram nódulos. Não houve contaminação do experimento, porque nenhuma das testemunhas apresentou nódulos em suas raízes.

As inoculações de suspensão de solo não promoveram aumento na produção de matéria seca da parte aérea (MSPA) e somente a testemunha que recebeu $\mathrm{N}$ (210 mg planta $^{-1}$ ) produziu maior MSPA, corroborando a ineficiência das populações nativas de rizóbio.

A população de rizóbio calculada pelo método das diluições sucessivas variou de $1,4 \times 10^{3}$ rizóbios por grama de solo (Amostra 1) a $4,2 \times 10^{3}$ rizóbios por grama de solo (Amostra 2) e, portanto, pode ser considerada relativamente alta.

Os 57 isolados recuperados a partir de nódulos das plantas de feijoeiro foram agrupados com base em suas características culturais (Quadro 2).

\section{Análise de proteínas totais por SDS-PAGE}

Os isolados formaram 6 grupos com nível de similaridade maior que $80 \%$ com base no perfil eletroforético de proteína total. O dendrograma de similaridade, obtido a partir dos perfis eletroforéticos dos isolados e das estirpes inoculantes e tipo, pode ser visualizado nas figuras 1 e 2 .

O grupo A foi formado por 47 isolados e a estirpe tipo BR 10.051 de Rhizobium leguminosarum bv 


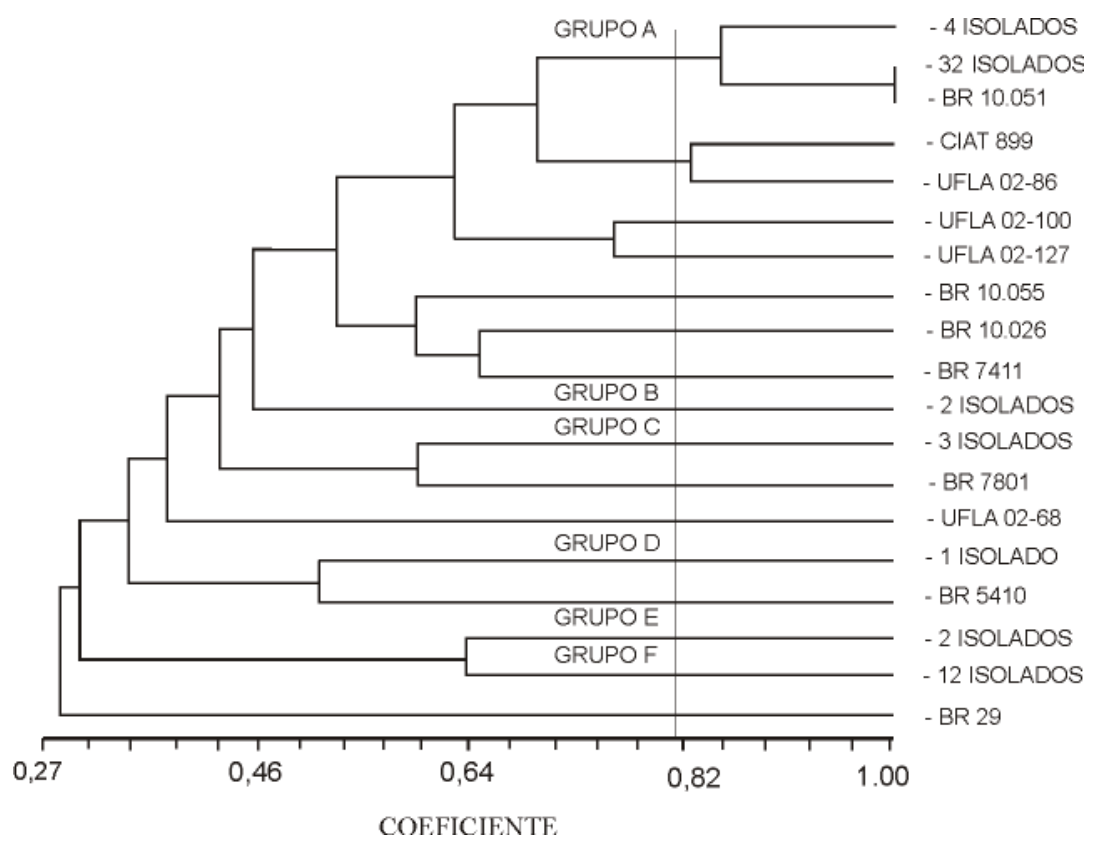

Figura 1. Dendrograma de similaridade construído com base nos perfis de proteína celular total de estirpes isoladas do solo da área em estudo, das estirpes inoculantes (CIAT 899, UFLA 02-68, UFLA 02a-86, UFLA 02-100 e UFLA 02-127) e das estirpes tipo ER 316ci0a ${ }^{\mathrm{T}}$ (BR 10.051-Rhizobium leguminosarum bv phaseoli); CNF 42 ${ }^{\mathrm{T}}$ (BR 10.026-Rhizobium etli); HAMBI 540 ${ }^{\mathrm{T}}$ (BR 10.055-Rhizobium galegae bv orientalis); NZP $4027^{\mathrm{T}}$ (BR 7411- Sinorhizobium meliloti); NZP 2213 ${ }^{\mathrm{T}}$ (BR 7801-Mesorhizobium loti); ORS $571^{\mathrm{T}}$ (BR 5410-Azorhizobium caulinodans) e referência BR 29-Bradyrhizobium elkanii., obtidas por eletroforese em gel de poliacrilamida (SDS-PAGE).

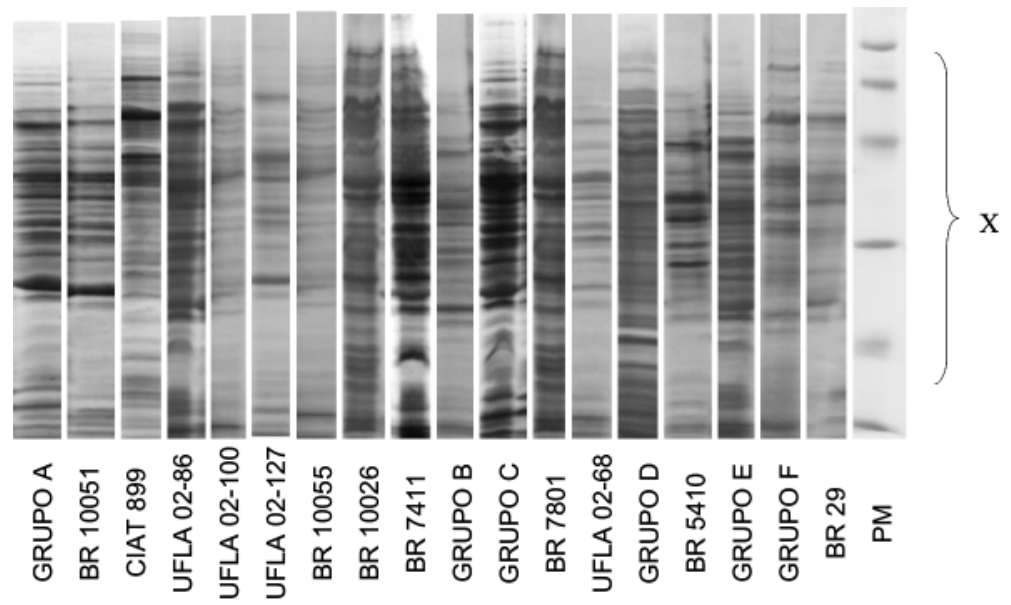

Figura 2. Perfis de proteína celular total de estirpes isoladas do solo da área em estudo, das estirpes de referência e das estirpes tipo obtidas por eletroforese em gel de poliacrilamida (SDS-PAGE). $\mathrm{X}=$ área utilizada - 15 bandas; PM = padrão de peso molecular LMWM.

phaseoli. Verificou-se que nenhuma estirpe inoculante, nem as estirpes tipo agruparam-se, a $80 \%$ de similaridade, com os demais isolados nativos da área em estudo.

A ocorrência de espécies de rizóbio que nodulam o feijoeiro é demonstrada por outros autores como sendo variável para cada tipo de solo ou região estudada. Andrade et al. (2000) verificaram maior ocorrência de
Rhizobium leguminosarum bv. phaseoli, em relação ao $R$. tropici, em solos que não receberam calagem e, portanto, com valores menores de $\mathrm{pH}$, o que também foi observado neste trabalho. Mhandi et al. (1999) obtiveram isolados de feijoeiro em solos da Tunísia, sendo $1 / 3$ classificado como $R$. gallicum, $1 / 3$ como $R$. etli e $R$. leguminosarum e o restante em outras espécies que nodulam o feijoeiro. O resultado deste 
trabalho contraria os encontrados por Hungria et al. (2000), que relataram o domínio de isolados com características de $R$. tropici nas regiões tropicais, considerando sua estabilidade genética, tolerância à acidez e altas temperaturas e corrobora os resultados obtidos por Pereira et al. (2000), que encontraram maior similaridade de isolados da Amazônia com Rhizobium leguminosarum bv. phaseoli do que com Rhizobium tropici.

\section{CONCLUSÕES}

1. A inoculação com as estirpes UFLA 02-86, UFLA 02-100 e UFLA 02-127 contribuiu, de forma significativa, para o aumento no rendimento e acúmulo de $\mathrm{N}$ ou grãos no feijoeiro e não diferiu da inoculação com a estirpe CIAT 899, recomendada pela RELARE.

2. A população nativa apresentou alta diversidade fenotípica. No entanto, não houve relação entre os grupos fenotípicos de perfil protéico total e caracterização cultural.

3. Com base no perfil protéico total, os isolados da população nativa foram classificados, em sua maioria, com $80 \%$ de similaridade, como Rhizobium leguminosarum bv. phaseoli.

4. As estirpes inoculadas e eficientes mostraramse fenotípicamente distintas das estirpes da população nativa.

\section{AGRADECIMENTOS}

Ao CNPq, pela concessão de bolsas de iniciação científica, mestrado e produtividade em pesquisa; a CAPES, pelas bolsas de mestrado e doutorado, e à FAPEMIG, pelo financiamento do projeto CAG113002.

\section{LITERATURA CITADA}

ANDRADE, N.; MURPHY, P.J; GILLER, K.E. Diversity and abundance of populations of bean-nodulating rhizobia as a function of liming and cropping history in acidic Brazilian soils. In: PEDROSA, F.O.; HUNGRIA, M.; YATES, M.G. \& NEWTON, W.E., eds. Nitrogen Fixation: from melecules to crop produtivity. Dordrecht, Kluweer, 2000. p.546.

ARAÚJO, R.S. Fixação biológica de nitrogênio em feijão. In: ARAUJO, R.S. \& HUNGRIA, M,, eds. Microrganismos de importância agrícola. Brasilia, Embrapa, 1994. p.91-120.
EMPRESA BRASILEIRA DE PESQUISA AGROPECUÁRIA EMBRAPA. Sistema brasileiro de classificação de solos. Brasília, 2000. 412p.

FAOSTAT, Banco de Dados da FAO. Disponível em: <http:// www.fao.com>. Acesso em 30/07/2003.

FRANCO, A.A.; PEREIRA, J.C. \& NEYRA, C.A. Seasonal patterns of nitrate reductase and nitrogenase activities in Phaseolus vulgari L. Plant Physiol., 63:421-424, 1979.

FRED, E.B. \& WAKSMAN, S.A. Laboratory manual of general microbiology. New York, McGraw-Hill Book Company, 1928. 143p.

GRAHAM, P.H. Stress tolerance in Rhizobium and Bradyrhizobium, and nodulation under adverse soil conditions. Can. J. Microbiol., 38:475-484, 1992.

HUNGRIA, M.; ANDRADE, D.S.; CHUEIRE, L.M.O.; PROBANZA, A.; GUTTIERREZ-MAÑERO, F.J. \& MEGIAS, M. Isolation and characterization of new efficient and competitive bean (Phaseolus vulgaris L.) rhizobia from Brazil. Soil Biol. Biochem., 32:1515-1528, 2000.

HUNGRIA, M.; CAMPO, R.J. \& MENDES, I.C. Benefits of inoculation of the common bean (Phaseolus vulgaris) crop with efficient and competitive Rhizobium tropici strains. Biol. Fertil. Soils, 39:88-93, 2003.

JACKMAN, P.J.H. Bacterial taxonomy based on eletrophoretic whole-cel protein patterns. In: GOODFELLOW, M. \& MINNIKIN, D., eds. Chemical methods in bacterial systematics. London, Academic Press, 1985. p.119-129.

LAEMMLI, U.K. Cleavage of structural proteins during the assembly of the head of bacteriofage T4. Nature, 227:680685,1970

MANDHI, R.; JEBARA, M.; AOUANI, M.E.; GHRIR, R. \& MARS, M. Genotypic diversity and symbiotic effetiveness of rhizobia isolated from root nodules of Phaseolus vulgaris L. grow in Tunisian soils. Biol. Fertil. Soils, 28:313320, 1999.

MARTÍNEZ-ROMERO, E.; SEGOVIA, L.; MERCANTE, F.M.; FRANCO, A.A.; GRAHAM, P. \& PARDO, M.A. Rhizobium tropici, a novel species nodulating Phaseolus vulgaris $\mathrm{L}$. beans and Leucaena sp. trees. Int. J. Syst. Bacteriol., 41:417-426, 1991.

MOREIRA, F.M.S. Caracterização de estirpes de rizóbio isoladas de espécies florestais pertencentes a diversos grupos de divergência de Leguminosae introduzidas ou nativas da Amazônia e Mata Atlântica. Itaguaí, Universidade Federal Rural do Rio de Janeiro, 1991. 152p. (Tese de Doutorado)

MOREIRA, F.M.S.; GILLIS, M.; POT, B.; KERSTERS, K. \& FRANCO, A.A. Characterization of rhizobia isolated from diferent divergence groups of tropical leguminosae by comparative polyacrilamide gel eletrophoresis of their toal proteins. Syst. Appl. Microbiol., 16:135-146, 1993.

MOSTASSO, L.; MOSTASSO, F.L.; DIAS, B.G.; VARGAS, M.A.T. \& HUNGRIA, M. Selection of bean (Phaseulous vulgaris L.) rhizobial strains for the Brazilian Cerrados. Field Crops Res., 73:121-132, 2001. 
OLIVEIRA, W.S. Interação Rhizobium/Feijoeiro sob as condições de agricultura de subsistência na região de Cunha-SP. Piracicaba, Escola Superior de Agricultura "Luiz de Queiroz", 1996. 68p. (Tese de Mestrado)

PEREIRA E.G.; LACERDA, A.M.; LIMA, A.S.; MOREIRA, F.M.S.; CARVALHO, D. \& SIQUEIRA, J.O. Genotypic, phenotypic and symbiotic diversity among rhizobia isolates from Phaseolus vulgaris L. growing in the Amazon region. In: TSBF report 1997-1998. Quênia, TSBF/UNESCO/ IUSB, 2000. p.86-87.

RAMALHO, M.A.P.; ABREU, A.F.B.; CARNEIRO, J.E.S.; GONCALVES, F.M.A.; SANTOS, J.B.; PELOSO, M.J.D.; FARIA, L.C. \&CARNEIRO, G.E.S. O "Talismã" de sua lavoura de feijoeiro. ??Local??, Embrapa, 2002. 4p. (Embrapa-CNPAF, Comunicado Técnico, 36)
SARRUGE, J.R. \& HAAG, H.P. Análises químicas em plantas. Piracicaba, Superior de Agricultura "Luiz de Queiroz", 1979. $27 \mathrm{p}$.

SLICE, D.E.; KIM, J. \& WALKER, J. NTSYS-Numerical taxonomy and multivariate analysis system: versão 1.80 . [S.l]:[s.n.], 1994.

STRALIOTTO, R. A importância da inoculação com rizóbio na cultura do feijoeiro. Embrapa, CNPAB, 2002. Disponível em: http:// www.cnpab.embrapa.br/pesquisa/ fbnlinocula_feijoeiro. html\#. Acesso em: 15/07/2003.

WOOMER, P.; BENNET, J. \& YOST. R. Overcoming the inflexibility of most-probable-number procedures. Agron. J., 82:349-353, 1990. 